\title{
Radioactive: Análise do potencial do filme como material de Divulgação Científica
}

\author{
Radioactive: Analysis of the potential of the fillm as a material for Scientific Dissemination \\ Radiactivo: Análisis del potencial de la película como material de Difusión Científica
}

Recebido: 21/12/2021 | Revisado: 28/12/2021 | Aceito: 05/01/2022 | Publicado: 16/01/2022

\author{
Ana Caroline Vieira Correia \\ ORCID: https://orcid.org/0000-0001-8330-578X \\ Universidade Federal de Itajubá, Brasil \\ E-mail: anacarolinevie@ hotmail.com \\ Crediana Chris de Siqueira \\ ORCID: https://orcid.org/0000-0001-8922-4972 \\ Universidade Federal de Itajubá, Brasil \\ E-mail: credianacsiqueira@gmail.com \\ Sara Carolayne Mendonça Salgado \\ ORCID: https://orcid.org/0000-0002-7943-8958 \\ Universidade Federal de Itajubá, Brasil \\ E-mail: sarinhacms@outlook.com \\ Willian Guimarães de Carvalho Costa \\ ORCID: https://orcid.org/0000-0002-5964-9782 \\ Universidade Federal de Itajubá, Brasil \\ E-mail: williancostag@unifei.edu.br
}

\begin{abstract}
Resumo
Os filmes vêm sendo utilizados como instrumento didático para apresentar o saber científico em sala de aula. A obra cinematográfica "Radioactive" lançada em 2019 retrata aspectos da vida da cientista Marie Curie e sua jornada científica juntamente ao seu marido Pierre. Nesse sentido, esse trabalho buscou identificar as possíveis contribuições do filme como instrumento de divulgação científica e apresentar seu potencial didático para utilização em sala de aula. Dessa forma, procurou-se compreender nas cenas do filme aspectos relacionados ao contexto da mulher na ciência, como o filme aborda o assunto radioatividade e identificar aspectos que retratam a atividade científica; para tal, utilizou-se a Análise Textual Discursiva para tratamento dos dados. Conclui-se que a utilização de obras cinematográficas gera envolvimento do público, e o filme apresenta significativo potencial para ser utilizado como um material de divulgação científica trazendo contribuições tanto para o processo de ensino e aprendizagem quanto para a democratização do conhecimento.
\end{abstract}

Palavras-chave: Divulgação científica; Filme; Radioactive; Marie Curie.

\begin{abstract}
Movies have been used as a didactic tool to present scientific knowledge in the classroom. The movie "Radioactive" released in 2019 portrays aspects of the life of scientist Marie Curie and her scientific journey with her husband Pierre. In this sense, this work sought to identify the possible contributions of the film as a tool for scientific dissemination and present its educational potential for use in the classroom. Thus, we tried to understand in the scenes of the film aspects related to the context of women in science, how the film approaches the subject of radioactivity and identify aspects that portray the scientific activity; for this, we used the Textual Discourse Analysis for data treatment. It is concluded that the use of cinematographic works generates public involvement, and the film presents significant potential to be used as a material for scientific dissemination bringing contributions to both the teaching and learning process and the democratization of knowledge.
\end{abstract}

Keywords: Scientific dissemination; Movie; Radioactive; Marie Curie.

\section{Resumen}

Las películas se han utilizado como herramienta didáctica para presentar los conocimientos científicos en el aula. La obra cinematográfica "Radiactivo" estrenada en 2019 retrata aspectos de la vida de la científica Marie Curie y su periplo científico con su marido Pierre. En este sentido, este trabajo pretendía identificar las posibles aportaciones de la película como herramienta de divulgación científica y presentar su potencial educativo para su uso en el aula. Así, se buscó comprender en las escenas de la película aspectos relacionados con el contexto de las mujeres en la ciencia, cómo la película aborda el tema de la radiactividad e identificar los aspectos que retratan la actividad científica; para ello, se utilizó el Análisis Textual del Discurso para el tratamiento de los datos. Se concluye que el uso de obras cinematográficas genera la participación del público, y la película presenta un potencial significativo para ser utilizada como material de divulgación científica aportando contribuciones tanto para el proceso de enseñanza y aprendizaje como para la democratización del conocimiento.

Palabras clave: Divulgación científica; Película; Radioactivo; Marie Curie. 


\section{Introdução}

Embora seja evidente a necessidade de conhecimento sobre ciência e tecnologia no mundo atual, vale ressaltar que, além de explicar e divulgar fenômenos, é necessário que o indivíduo tenha acesso ao conhecimento técnico e científico para criar um diálogo e interagir dentro da sociedade (Castelfranchi, 2010). O papel da Divulgação Científica (DC) consiste em levar as diferentes ideias e fenômenos para um maior número de pessoas, com o objetivo de se colocarem como cidadãos críticos e reflexivos diante da sociedade.

É preciso refletir sobre a forma como a ciência está sendo apresentada à população, qual a linguagem utilizada, como ampliar as discussões científicas para diferentes públicos. Neste ponto, Nascimento \& Rezende Júnior (2010) indicam que "a DC não é uma simples tradução de conhecimentos científicos que seriam adaptados a um público que não domina determinados conceitos ou procedimentos próprios da ciência". Segundo os autores a DC é um resultado da atividade discursiva produzida em contextos diferentes daqueles em que se produz o conhecimento científico.

Ao levar a ciência e a tecnologia para a sociedade, há algumas implicações que contribuem para democratizar o conhecimento e para impulsionar a ciência. Para a nação há um estímulo de interesse do público jovem, e consequentemente, um maior número de trabalhadores especializados que se interessam por aspectos científicos, para a própria ciência percebe-se o apoio social, a aceitação, o que contribui para quebrar barreiras e incentivar a colaboração, e para o povo coopera para a educação pública e democrática (Castelfranchi, 2010).

Como forma de caracterizar a DC, Nascimento e Rezende Júnior (2010) em sua pesquisa evidenciaram que alguns autores utilizam das características de textos de divulgação científica (TDC) para defini-la, tais como: possuir uma linguagem distinta do discurso científico, com menos formalismo e aproximando-se da linguagem cotidiana; possuir objetivos próprios, incluir conteúdos extra curriculares; possuir um público-alvo diversificado e amplo, fazendo uso de diversos meios de transmissão. A escola e o educador possuem um papel essencial na condução dos alunos, o que implica na utilização de alguns recursos de DC durante as aulas.

Damos destaque a utilização de filmes como instrumento, principalmente por estar presente no cotidiano dos alunos, ser de fácil acesso e contribuir com a imaginação e criatividade. Costa (2009) enfatiza que o cinema é visto como forma de entretenimento e obra artística, mas que também faz parte do cotidiano da escola e contribui para o espaço pedagógico como um material didático, permitindo caminhos que levam o professor a formar um saber científico dentro da sala de aula.

Segundo Vicentino e Sant'Ana (2010), os filmes são utilizados a muito tempo por despertarem o interesse, por estimular o pensamento crítico, ampliar as opiniões, e por despertar a busca do saber. Sendo também possível despertar no público o "[...] interesse pela ciência, chegando mesmo a estabelecer algum nível de alfabetização científica ou mesmo motivação para carreiras científicas" (Suppia, 2006). Dentro do ambiente escolar Silva e Kawamura (2001), destacam o potencial que a utilização de filmes possui como meio que possibilita a discussão de ideias e conceitos, propiciando situações ricas de novos significados como: debater notícias, verificar sua veracidade e discutir criticamente suas consequências, além de estimular a leitura.

Compreendemos como potencial didático os recursos e estratégias que os professores podem adotar buscando novas possibilidades para aprendizagem. Para Abud (2003) as produções fílmicas podem atrair os alunos para aulas, permite compreender melhor aspectos pautados nos currículos escolares, além de que possibilita abordar questões culturais e sociais, proporcionando que o aluno desenvolva uma análise mais crítica do mundo. Assim, esses recursos são potenciais didáticos pois podem auxiliar os professores em suas aulas através de propostas didáticas, podendo contribuir com a aula do professor e com a construção do conhecimento do estudante.

De acordo com Moran (1995), a vantagem pedagógica da utilização de filmes inclui diferentes propostas como: sensibilização, ilustração, simulação, conteúdo de ensino, produção, avaliação e integração/suporte, desta forma, o objetivo 
desta pesquisa é identificar as possíveis contribuições do filme Radioactive como um instrumento de DC e seu potencial didático. Para tal, buscou-se compreender como o filme representa o contexto da mulher na ciência, como a radioatividade é abordada na obra e como os aspectos da atividade científica são apresentadas, para que se pudesse avaliar o potencial do filme como material didático, a fim de fornecer uma orientação para que professores possam utilizar o filme em atividades didáticas reconhecendo alguns desses potenciais e para além de um recurso de diversão.

\section{Divulgação Científica e o Ensino de Ciências}

A ciência está presente no cotidiano das pessoas, trata-se, portanto, de "uma prática social e, como tal, não pode ser vista como independente ou desvinculada do sujeito e das ideologias que o constituem. Do mesmo modo, a Ciência não surge do acaso, ela é fruto de um processo cultural e histórico" (Cunha \& Giordan, 2009a, p. 2).

Como apontado pela concepção de Silva (2009) na atualidade, a educação escolar e a comunicação de massa se relacionam de forma muito intensa, porém, ainda existe um conflito que coloca o aprendizado fora do contexto escolar como não suficientemente confiável.

Para Pin et al. (2015) a Divulgação Científica (DC) tem como objetivo a aproximação de conhecimentos do público não especialista, recorrendo a práticas que podem conciliar o ambiente escolar com temas que fazem parte do contexto social dos alunos, e que indicam problemas que ao serem abordados na escola, possibilitam que os educandos reconheçam que fazem parte deste contexto e construam conhecimentos e habilidades que podem melhorar a qualidade de vida da população e ao mesmo tempo cooperar com o desenvolvimento do país. Os autores ressaltam ainda que a DC pode ocorrer em ambientes formais, informais e não-formais de ensino, e em distintas situações de aprendizagem.

Quando utilizada como ferramenta de ensino, sobretudo no ensino de ciências, a DC pode ter diferentes propósitos que variam de acordo com os objetivos de ensino estabelecidos pelo professor, dentre outros eles podem ser de contextualização histórica, de promoção de debates, metacognição e pesquisa (Lima \& Giordan, 2017).

Mas para tal implementação, é necessário que o professor, na qualidade de formador, tenha um contato prévio e conhecimentos sobre os recursos, estratégias de linguagem da DC, e "se preocupe em fazer uma leitura crítica, assim como as articulações necessárias" (Ferreira \& Queiroz, 2012, p. 10) uma vez que, o contato prévio com o tema, possibilita uma ampla reflexão sobre como tais materiais podem auxiliar o processo de ensino-aprendizagem.

Além das variadas ferramentas por meio das quais a DC pode ser empregue em atividades didáticas, os recursos midiáticos têm se mostrado frequentes em situações de ensino e estimulam jovens e crianças na construção da cultura científica; tais ferramentas, têm a potencialidade de promover a desmistificação da ciência na qualidade de ação humana, capaz de ser realizada independentemente da condição social, gênero ou idade (Lisboa Júnior, et al., 2015).

Autores como Pinheiro e Londero (2021) apontam que a utilização de filmes pode auxiliar os professores a instigar a curiosidade dos alunos para os fatos discutidos, e quando bem selecionados, podem propiciar uma perspectiva diferente sobre as ciências levando-os a ponderar acerca de indagações que desdobram-se os temas abordados pelos docentes. Assim, é importante que o ensino de ciências proporcione ao estudante aprender ciências como também compreender a investigação científica como um todo, de forma que ele seja capaz de interpretar o mundo e possa exercer a cidadania de forma crítica e participativa (Sousa et al., 2020).

\section{A Ciência no Cinema}

De acordo com Reznik et al. (2019) é comum que as obras cinematográficas reproduzam uma imagem estereotipada sobre o cientista, na qual ele é normalmente representado como um homem de jaleco, óculos e cabelo bagunçado, com traços de genialidade e loucura, inserido em um trabalho solitário de laboratório repleto de artefatos. No entanto, essas representações 
do audiovisual trazem diversas implicações para a construção social da imagem do cientista, uma vez que são uma das principais influências para a percepção pública da ciência e do cientista (Reznik et al., 2019).

Kosminsky e Giordan (2002) apontam que a visão de mundo dos estudantes pode ser influenciada pelas expressões de sua cultura, indicando um papel de relevância da mídia no desenvolvimento de concepções sobre a ciência. Para os autores, as mídias difundem o conhecimento para todos os estratos sociais, no entanto, o apelo ao espetáculo sensibilizador das emoções prevalece ao apresentar o processo da produção científica.

Embora a mídia ainda tenha influência em promover algumas concepções sobre a imagem da ciência e do cientista nas obras cinematográficas, algumas obras também podem ser utilizadas como ferramenta para promover a DC, sendo capaz de colaborar com a contextualização e enquadrar conceitos científicos dentro de uma narrativa fictícia, proporcionando a compreensão do tema por parte do público (Silva \& Calafate, 2021).

Dessa forma, as obras de audiovisual, como os filmes, vêm sendo utilizados por professores como ferramenta pedagógica para popularizar a ciência, uma vez que permite abordar na sala de aula aspectos que podem colaborar para uma imagem mais adequada do conhecimento científico, como apresentar questões da história da ciência a partir de uma obra ficcional ou bibliográfica.

Quanto à imagem apresentada do cientista, em que ele é frequentemente representado como um homem, vem da ausência de mulheres na ciência, uma vez que a ciência enquanto atividade humana tende a deixar explicita as diferenças existentes entre homens e mulheres, na qual essas diferenças impediram e dificultaram que mulheres ocupassem espaços predominantemente destinado aos homens, como as áreas das ciências (Albuquerque \& Silva, 2019). Entre os laureados com prêmio Nobel, poucas mulheres até hoje foram prestigiadas com esse reconhecimento, sendo alguma delas Marie Curie (Nobel de física em 1903 e química em 1911), Irene Curie (Nobel de química em 1935), Maria Goeppert-Maye (Nobel de física em 1963) e Dorothy Crowfoot (Nobel de química em 1964), no entanto, ainda hoje a premiação de homens continua sendo predominante no Nobel (Cunha \& Giordan, 2008b).

Para Cunha e Giordan (2009b) apesar das mulheres serem minorias das carreiras científicas, há um número crescente de mulheres que se dedicam à ciência. De acordo com os autores, o cinema percebeu que a mulher está cada vez mais decidida a fazer parte da comunidade científica, e nas últimas décadas, vem buscando representar em suas telas a mulher como protagonista dos filmes e das pesquisas científicas.

\section{Metodologia}

O presente trabalho tem cunho qualitativo, o qual na concepção de Mól (2017, p. 502) trabalhos desta natureza compreendem a "ciência como uma área do conhecimento que é construída pelas interações sociais no contexto sociocultural que as cercam. Por isso, seu foco é compreender os significados dos fenômenos a partir de quem os vivenciam, considerando tempos e espaços de atuações e reflexões". A metodologia qualitativa é estudada e descrita por pesquisadores como Estrela (2018) e Pereira et al. (2018).

A obra intitulada "Radioactive" trata-se de um filme, dirigido por Marjane Satrapi e roteirizado por Jack Thorne, que foi baseado na história de vida de Marie Curie, cientista Polonesa vencedora do Prêmio Nobel de Física e Química. O filme foi lançado no ano de 2019 e é disponibilizado na plataforma de streaming "Netflix" com a seguinte sinopse: "Movida por uma mente brilhante e uma grande paixão, Marie Curie embarca em uma jornada científica com o marido, Pierre. Suas descobertas vão mudar o mundo".

O gênero da obra é descrito como "Filmes sobre questões sociais, Britânico, Filmes baseados na vida real, Filmes baseados em livros, Dramas" e tem como elenco: Rosamund Pike, Sam Riley, Aneurin Barnard, Anya Taylor-Joy, Simon Russell Beale, Katherine Parkinson, Sian Brooke, Ariella Glaser. O poster de divulgação do filme pode ser identificado na 
Figura 01, na qual é relevante se observar que a protagonista segura em suas mãos um frasco com uma porção de uma substância que emite uma luz esverdeada que representa o elemento químico descoberto.

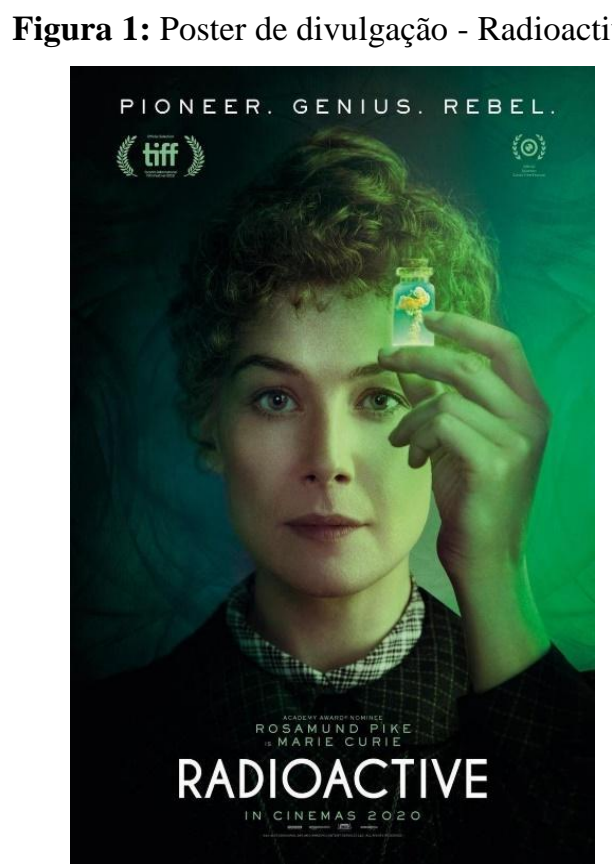

Fonte: Catálogo Netflix (2021).

Para a coleta dos dados foram buscados no filme trechos que representassem os contextos definidos, sendo eles: A mulher na ciência, radioatividade e a construção da ciência. Para cada um desses aspectos foram selecionadas 3 cenas diferentes na qual consideramos pertinentes para a abordagem desses tópicos. Posteriormente para análise dos trechos e cenas, foi empregue o método de Análise Textual Discursiva (ATD) que é composto pela atribuição de significados, pelo estabelecimento de relações entre os contextos selecionados e pela construção de novas concepções acerca do tema tratado; quanto a natureza das categorias, podem ser consideradas como a priori, uma vez que se conheciam previamente os temas de análise (Moraes, 2003).

\section{Resultados e Discussão}

Partindo dos temas selecionados para discussão, buscou-se no filme cenas e falas que pudessem ser caracterizadas como pertencentes às categorias estabelecidas, posteriormente relacionou-se as cenas com o potencial didático atribuído a cada uma delas de acordo com o aporte teórico deste trabalho. As categorias criadas foram pensadas a partir dos temas que estão mais evidentes ao longo do filme e que podem ser tratados a partir de recursos da DC.

\section{- $\quad$ O contexto da mulher na ciência}

Um dos aspectos presentes no filme está relacionado ao papel da mulher na ciência. Assim, nesta categoria identificamos trechos que remetem às dificuldades encontradas por Marie Curie ao se inserir em ambientes científicos, que na época eram totalmente dominados por homens. O primeiro diálogo acontece entre Marie e o professor Lippmann (04'58") discutindo sobre a utilização e organização do laboratório. Marie compartilhava, com muitos homens, a utilização do laboratório de ciência na Universidade de Paris, onde era a única mulher entre os 23 cientistas. A Figura 2 busca ilustrar esse momento mencionado, na qual é relevante se observar que a personagem é a única mulher em uma sala que conta com a 
presença de vários outros homens.

Figura 2: Marie e o professor Lippmann discutindo sobre a utilização e organização do laboratório.

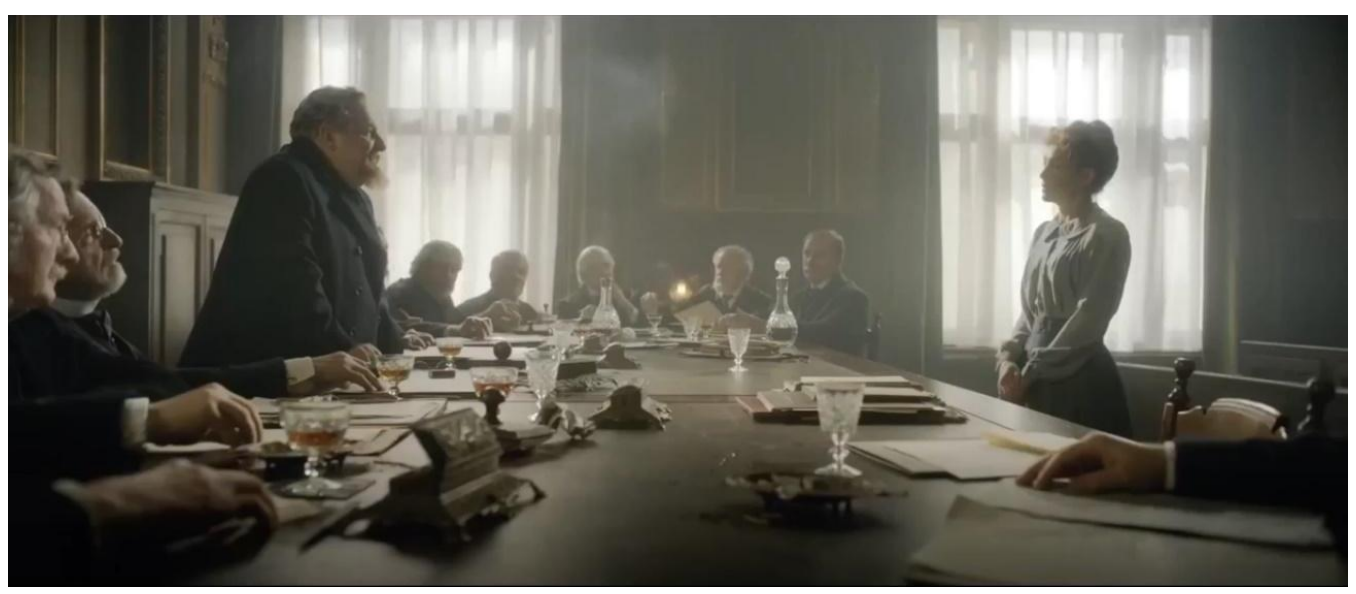

Fonte: Netflix (2021).

Professor: Então precisará montar seu laboratório, Srta. Sklodowska.

Marie: Não tenho verbas.

Professor: Sua falta de prudência em me apresentar exigências constantemente é algo que vai nos ensinar uma lição valiosa.

Ao analisarmos o modo como a mulher é representada na obra e o modo como sua vida pessoal e o contexto no qual ela está inserida interferem nos rumos que seu destino toma ao longo do filme, inevitavelmente integramos a atividade científica com questões sociais, entendendo que a ciência é uma atividade humana e atravessa suas concepções, como apontado por Cunha e Giordan (2009a; 2009b). Deste modo, as cenas que apresentam Marie sendo descredibilizada pelo Professor Lippmann que pede sua saída do laboratório, interrompendo suas falas e utilizando tom de soberba para com a cientista, relatam de forma bastante representativa as dificuldades que as mulheres enfrentaram em tempos passados - e que muitas ainda enfrentam atualmente - inicialmente para ter acesso à educação e posteriormente para serem reconhecidas por seus trabalhos.

Um outro ponto a ser discutido, refere-se às duas indicações da descoberta de Marie para o prêmio Nobel (43'31" $\mathrm{e}$ 80' 35'), conforme é apresentado pela Figura 3. Os grandes gestores da ciência não viam como algo favorável o reconhecimento de uma mulher para ganhar um prêmio que a priori era destinado somente a homens. Além disso, é possível perceber que Marie era julgada constantemente pela sua vida social, por pertencer a outro país e por ser uma mulher buscando reconhecimento na ciência.

A Figura 3 representa o momento mencionado. Nela é interessante observarmos que a protagonista segura uma das filhas no braço, enquanto o marido fala da conquista. 
Figura 3: Momento em que Marie e Pierre conversam sobre a indicação ao prêmio Nobel.

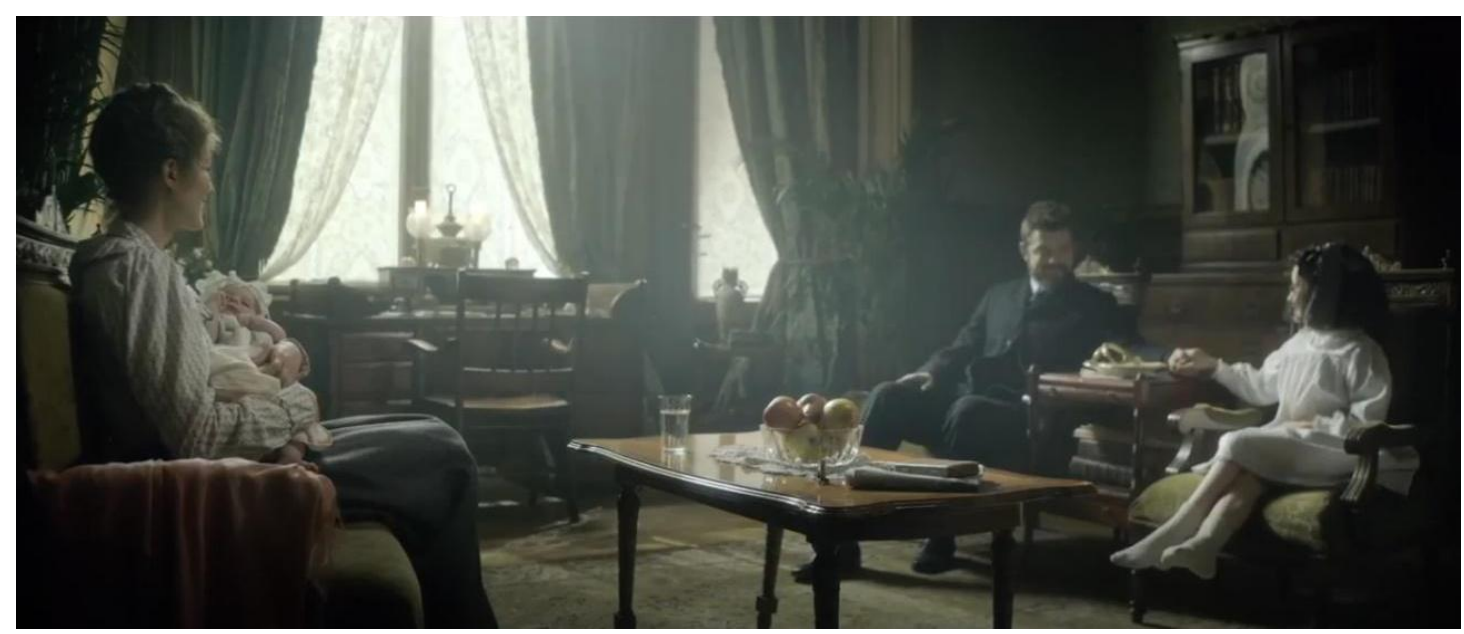

Fonte: Netflix (2021).

Pierre: Nosso trabalho foi indicado para o Prêmio Nobel. Pela descoberta da radioatividade. A comenda só menciona meu nome. E eu disse que, se ganharmos um Prêmio Nobel, ganharemos juntos.

A apresentação das dificuldades enfrentadas pelas mulheres colocada pelo filme pode representar possibilidades para que o professor, em sala de aula, atribua ao filme como material de divulgação científica os propósitos de contextualização histórica e a promoção de debates com seus alunos (Lima \& Giordan, 2017), trazendo questões que perpassam pelo cotidiano e que os instiguem a construir novas concepções, como por exemplo o fato de que a cientista entra para a história com o sobrenome do marido, desta forma sem se considerar a trajetória dela até se casar.

A terceira fala envolve novamente Marie e o professor Lippmann (59'36'). Após o falecimento de seu marido, que era professor da Universidade de Paris, a cientista recebeu o convite para tomar o seu cargo como primeira professora mulher. A cena descrita é representada na Figura 04, na qual a personagem está novamente diante de uma mesa composta por homens.

Figura 4: Marie Curie ao receber o convite para ser a primeira mulher professora da Universidade de Paris.

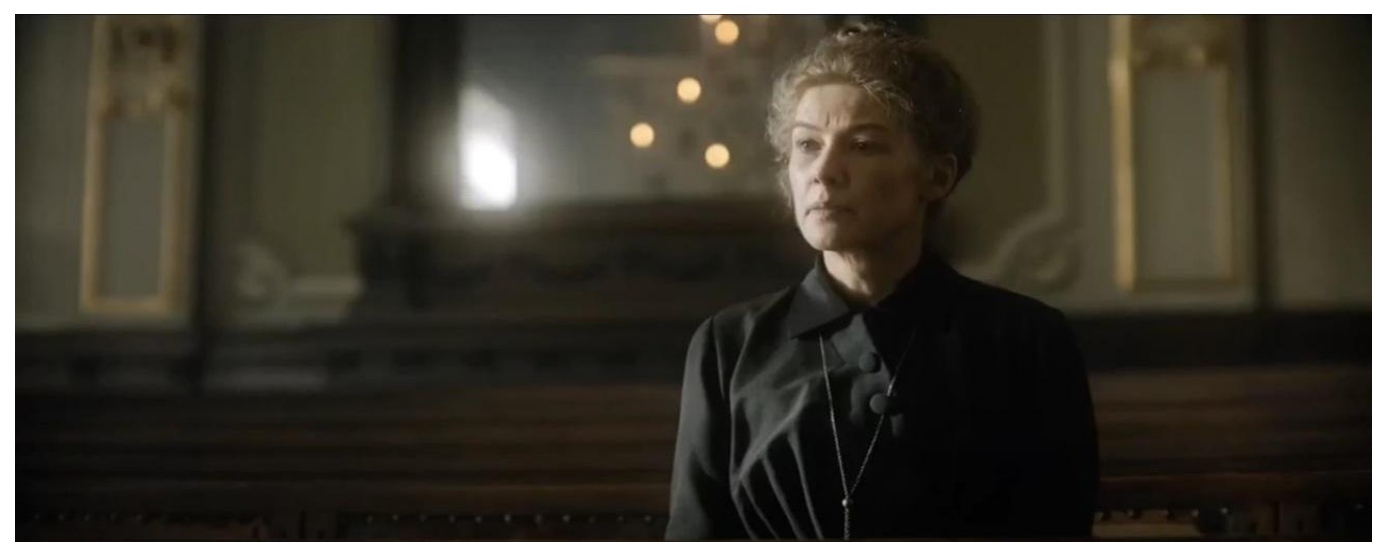

Fonte: Netflix (2021)

Marie: E se eu não quiser?

Professor: Será uma candidata a menos para considerar.

Marie: Quero ser considerada pelos meus méritos. Se quiserem dar por pena, não. Se quiserem me dar para cumprir obrigação, não. 
Desta forma, como apontado por Lisboa Júnior et al. (2015) a ciência pode ser realizada pelos seres humanos independentemente de seu gênero, uma vez que o conhecimento é um direito de todos, sendo assim, por mais que as situações impostas a Marie no filme dificultaram seu reconhecimento, a personagem não desistiu e conseguiu alcançar resultados que foram satisfatórios; portanto, a utilização do filme como base para discussão sobre a forma como a mulher conquistou e vem conquistando cada dia mais seu espaço na ciência representa uma potencialidade gigantesca de promover nos alunos a reflexão de que todos têm os mesmos direitos e que a ciência não é uma atividade neutra que independe das concepções de seus atores.

\section{- A radioatividade}

O tema radioatividade está presente no filme devido à história de Marie, porém no mundo real não é um tema de fácil compreensão, uma vez que se utiliza de conceitos técnicos e termos específicos.

No filme, uma das cenas se passa em um jantar (17’20") no qual a conversa entre os participantes se volta para as pesquisas de Marie e Pierre, representada pela Figura 5. Inicialmente as explicações dadas por ambos sobre os processos científicos são realizadas em linguagem formal e acadêmica, porém, como a outra participante da conversa não está inserida neste meio, Marie faz o uso de uma analogia para facilitar a compreensão do tema. Nesta cena, representada pela Figura 05, é relevante se observar que Marie, assim como todos os outros personagens estão conversando após um jantar e a protagonista e seu marido respondem às questões da outra convidada.

Figura 5: Marie em uma conversa explicando sobre radioatividade.

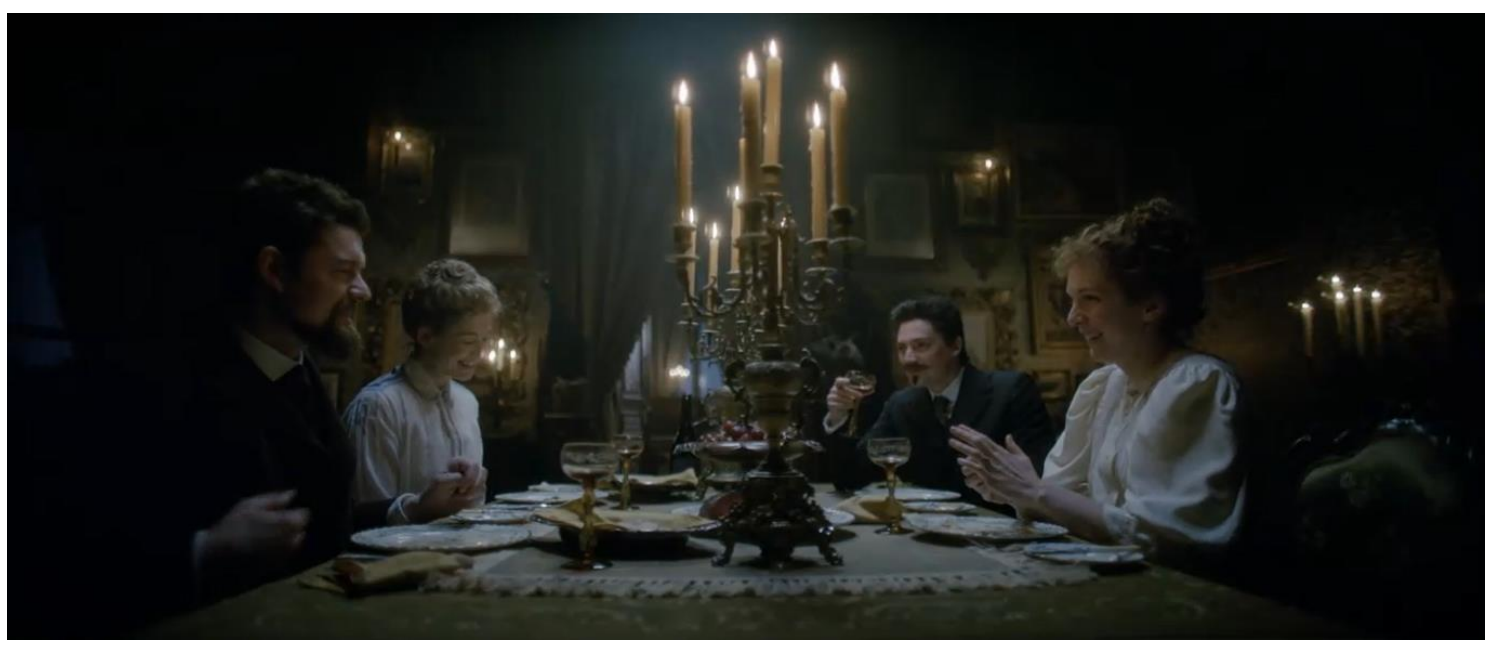

Fonte: Netflix (2021).

Marie: Imagine uma uva. Como a transforma em vinho?

Moça: É só esmagar e fermentar.

Marie: Sim, imagine uma uva se esmagando, se fermentando e mudando o próprio ser. E se eu dissesse que enquanto a uva se transforma em vinho, libera uma poderosa onda de energia. Um poder que faz as coisas acontecerem. Ficaria animada, não é?

A utilização de analogias é bastante comum em aulas de ciências, uma vez que o resgate de elementos presentes no cotidiano dos alunos auxilia na compreensão de conceitos, sendo capaz de promover maior interação entre o cientista e o sujeito não especialista.

Como apontado por Silva e Calafete (2021), as obras cinematográficas podem contribuir com a contextualização de 
conceitos científicos, além disto, tendo em vista que um dos principais objetivos da DC é de tornar acessível os conhecimentos que em sua maioria estão em posse apenas de especialistas, a cena destacada representa um potencial didático que evidencia a forma que a transposição desses conhecimentos pode assumir.

Durante todo o filme a menção ao rádio aparece, seja na forma de explicações dos conceitos que envolvem o rádio, seja nas cenas que apontam seus benefícios e malefícios. O filme utiliza várias cenas que provocam reflexões a respeito do elemento, deixando claro os efeitos tóxicos causados pela exposição à radiação.

A presença no filme do novo elemento químico também abre espaço para discussões sobre a radiação. Em uma das cenas Marie e Paul conversam em um ambiente escuro (28'22”) em que se vê nitidamente que a pequena quantidade de produto em uma placa Petri emite uma luz esverdeada que é capaz de iluminar os rostos de ambos, de acordo com o apresentado pela Figura 06, detalhe que pode ser observado nitidamente na cena.

Figura 6: Marie mostrando para Paul a substância radioativa, rádio.

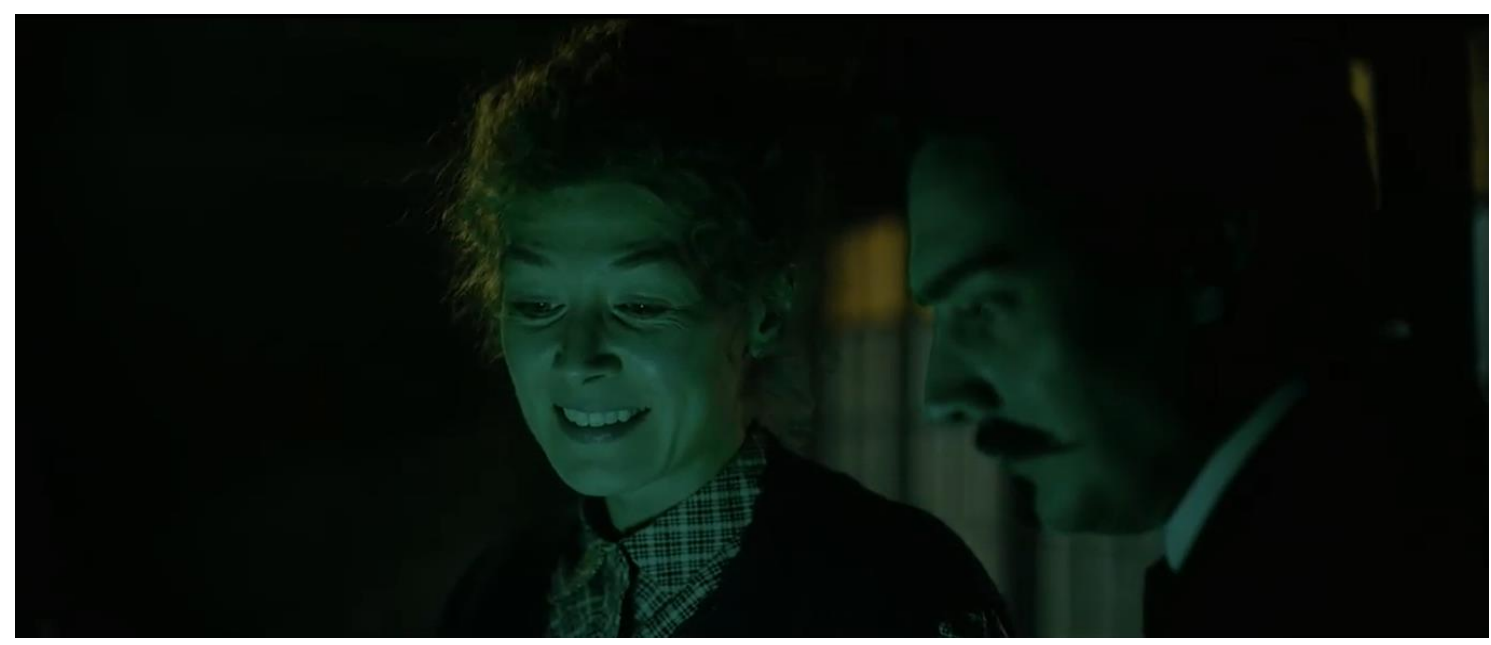

Fonte: Netflix (2021).

Marie: Paul. É rádio.

Paul: Rádio.

Marie: Um pouquinho de rádio. Tirado de quatro toneladas de pechblenda. Há mais para encontrar, mas... (sopro) não é a coisa mais linda que já viu?

A luz no rosto dos personagens nesta cena, abre espaço para a discussão de que a radiação pode ser emitida por meio da luz. Pinheiro e Londero (2021) discutem o potencial que os filmes têm de auxiliar professores a despertarem a curiosidade nos alunos, desta forma em acordo com os autores a cena pode proporcionar discussões sobre os conceitos de radiação, como a radiação é emitida, se a luz verde é emitida pelo próprio rádio, se a substância no vidro de Petri é pura, e sobre aspectos da história da ciência e da própria química.

A emissão de luz representada na cena e a apresentação que Marie faz a Paul do elemento rádio contribuem com a construção de uma nova concepção de ciência e do próprio cientista (Reznik et al., 2019), uma vez que é colocado na fala que quatrocentas toneladas de minério resultaram em apenas uma pequena quantidade do elemento, evidenciando que a conquista de resultados científicos também possui limitações, e além disso, o fato de uma mulher apresentar o resultado a um homem, contribui com o rompimento do estereótipo de gênero atribuído ao cientista pela sociedade.

Na cena em que Marie e Pierre conversam sobre as possibilidades que a descoberta do rádio pode proporcionar, 
(34'12”), mostrada pela Figura 7, Pierre lista alguns elementos criados pela população que passaram a conter em seu nome a palavra radioativo como forma de promover a popularização daqueles produtos, visto que o trabalho do casal Curie estava sendo amplamente divulgado e reconhecido. Nesta cena deve-se observar a variedade de produtos criados pela população da época que passou a conter no seu nome o termo radioativo, Pierre mostra a Marie alguns deles.

Figura 7: Marie e Pierre dialogando sobre produtos que levam em seu nome a palavra radioativo.

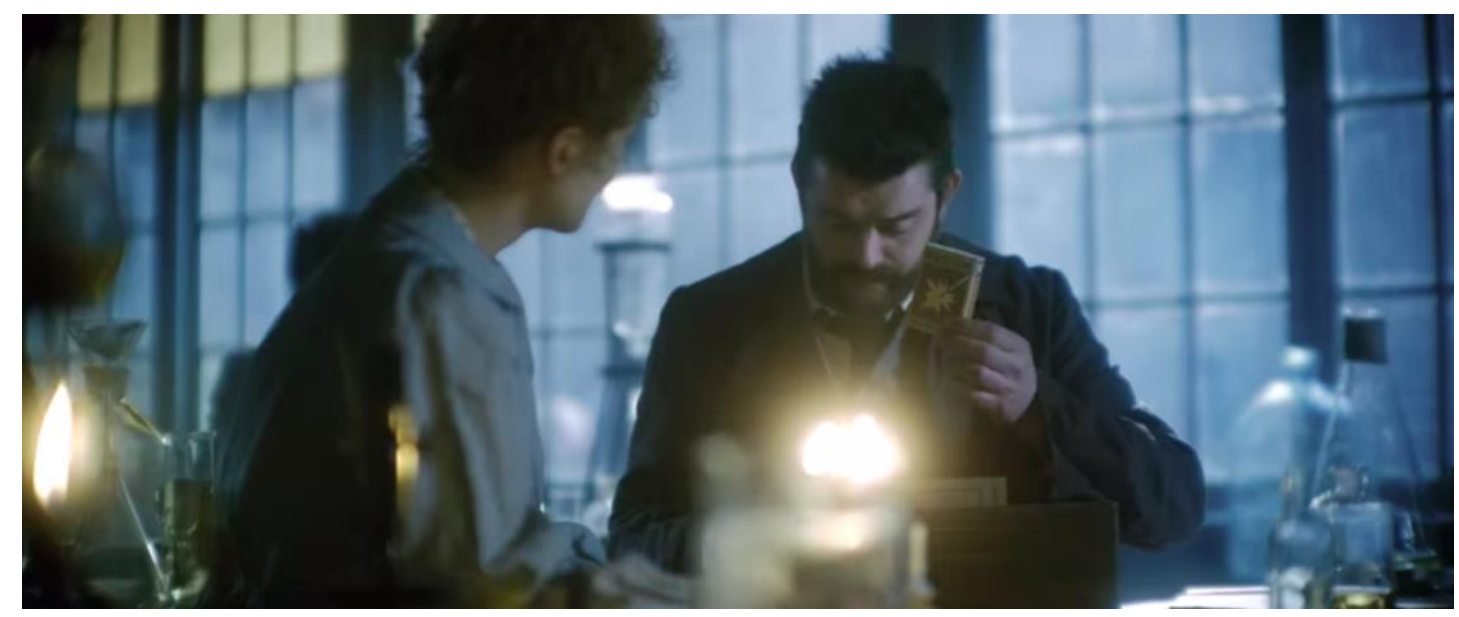

Fonte: Netflix (2021).

Marie: Não adianta confiar nos outros para isso.

Pierre: As pessoas veem as possibilidades, pode acreditar.

Pierre: Fósforos radioativos. Há cigarros radioativos. Chocolate radioativo, pasta de dente radioativa. Tem uma carta aqui sobre pó de maquiagem Radioativo. A Loie Fuller quer uma jaqueta radioativa para dançar. Não se preocupe, eu disse que não fazemos jaquetas. Soube que há uma dança na Broadway baseada no nosso trabalho? $O$ "Piff-Paff-Pouf".

Marie: $O$ que nós fizemos?

Nesta cena, fica claro que a população da época em busca de promover a venda de seus produtos acrescentava o termo radioativo a eles, mesmo não conhecendo o que seria a radiação ou quais as suas propriedades, tendo uma visão ingênua dos conceitos. Esta cena provoca reflexões sobre o papel da educação e da DC para a sociedade, uma vez que o emprego de termos desconhecidos a produtos é uma forma de persuadir as pessoas, tomando a ciência como algo que nunca apresenta falhas, com aspectos sempre positivos.

Ao considerar os documentos educacionais e as intenções de formar uma sociedade composta por cidadãos críticos, capazes de compreender, aplicar e utilizar os conhecimentos a seu favor e em benefício da sociedade, compreende-se que ainda é necessário fornecer bases que os tornem capazes de debater temas específicos, discutir sobre temas socioambientais, socioculturais, sociocientíficas, entre outros, para promover o desenvolvimento intelectual, econômico e social do país.

Neste sentido, é necessário que o professor considere questões do gênero, uma vez que como apontado por Ferreira \& Queiroz (2012), uma boa prática docente deve se preocupar em utilizar materiais previamente escolhidos, planejados para atingir seus objetivos, sendo este um dos caminhos para formar os cidadãos esperados pela sociedade.

- Aspectos sobre a atividade científica

O filme também apresenta diversos aspectos sobre o desenvolvimento da ciência, como seu caráter colaborativo, a 
importância do financiamento de pesquisas e as influências sociais, políticas e econômicas das pesquisas científicas. Esses aspectos mencionados podem ser observados nos seguintes trechos.

Em uma das cenas iniciais do filme (10’10”) ocorre um diálogo entre Marie e Pierre Curie, na qual Pierre a convida para trabalhar em seu laboratório de pesquisa. No entanto, Marie com receio de julgamentos demonstra resistência para aceitar tal proposta. A cena é representada pela figura 08 , na qual apresenta a personagem conhecendo o laboratório de Pierre, que era composto até o momento por uma equipe inteiramente masculina.

Figura 8: Pierre apresenta seu laboratório de pesquisa à Marie.

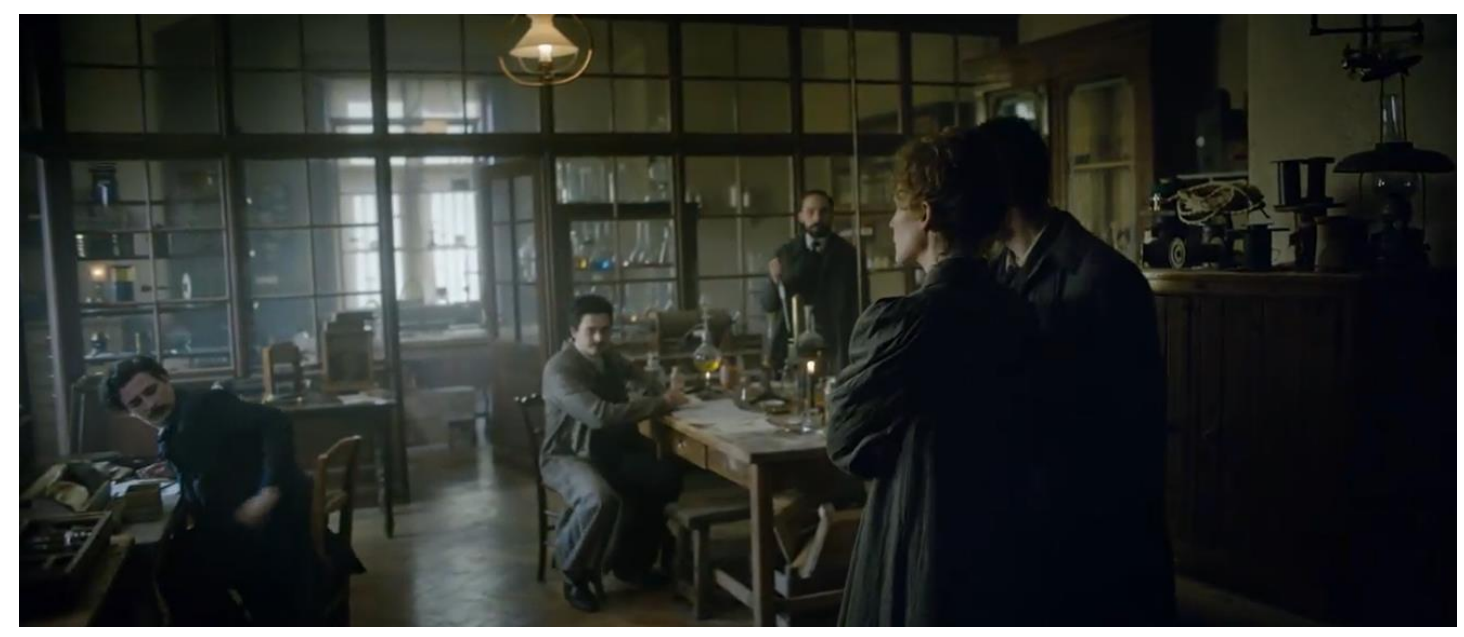

Fonte: Netflix (2021).

Pierre: Gosto de compartilhar ciência. Trabalhando juntos...

Marie: Não vou tolerar.

Pierre: Precisará aprender a tolerar. Gosto de colaboração. Vou me interessar pelo seu trabalho e gostaria que se interessasse pelo meu.

Nessa cena se evidencia o caráter colaborativo da ciência, em que se pode compreender que os cientistas, em sua maioria, trabalham de forma colaborativa e que essa parceria entre os pesquisadores também é significativa para o desenvolvimento das pesquisas científicas. Sendo assim, reconhece-se o potencial didático de se promover uma argumentação de que como apontado por Lisboa Júnior et al. (2015) a ciência é uma atividade humana e que envolve pessoas que possuem conhecimentos prévios diferentes e que contribuem de formas variadas para seu desenvolvimento.

Em outro momento, o filme apresenta Marie e Pierre em uma comunicação científica da Academia Francesa de Ciências (29'07”), conforme revela a figura 9. Nessa cena, os dois cientistas comunicam o resultado de suas pesquisas para a comunidade científica francesa, na qual apresentam como resultado de seus trabalhos o polônio e rádio, conforme aponta a Figura 9, assim como o trecho a seguir. 
Figura 9: Marie e Pierre comunicando o resultado de suas pesquisas à comunidade científica francesa.

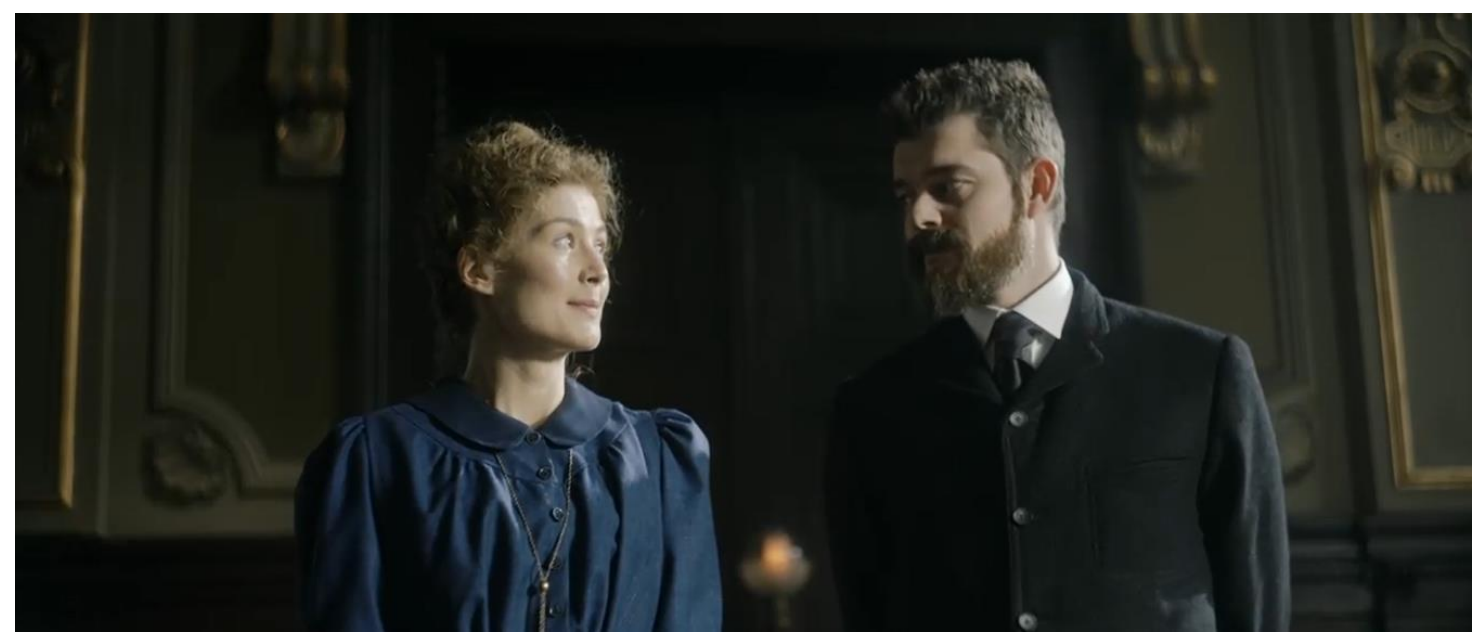

Fonte: Netflix (2021).

Pierre: Achamos que encontraríamos um novo elemento. Estávamos errados. Levou quatro anos, quatro toneladas de pechblenda, 40 toneladas de produtos químicos corrosivos e 400 toneladas de água. [...]

Pierre: Estamos aqui para apresentar dois novos elementos: Polônio e rádio.

A comunicação científica é uma prática muito comum e importante para cientistas, pois é nessas ocasiões que os pesquisadores compartilham os resultados ou andamento de seus trabalhos com seus pares. Além do mais, é relevante compreender a existência de uma comunidade científica, uma vez que ela tem um papel indispensável nos processos da ciência, de avaliar os conhecimentos científicos como também de gerar novas ideias. Dessa forma, o filme traz essa representação que é pertinente para uma compreensão apropriada do trabalho científico e que tem o potencial didático de contribuir com a construção de uma percepção pública do meio científico, como apontado por Reznik et al. (2019).

Outra cena que representa um aspecto importante da ciência, é no discurso narrado por Pierre ao ser laureado com o prêmio Nobel (45’06”), apresentada pela Figura 10. A cena da premiação intercala com cenas dos bombardeamentos que ocorreram em Hiroshima e Nagasaki, como forma de apresentar que a ciência não é salvacionista, mas que ela serve a interesses, na qual seus resultados podem solucionar problemas da humanidade como também gerar problemas à sociedade, dependendo da forma e de quem está usufruindo de seus resultados. 
Figura 10: Pierre discursando em Estocolmo ao ser laureado com o prémio Nobel.

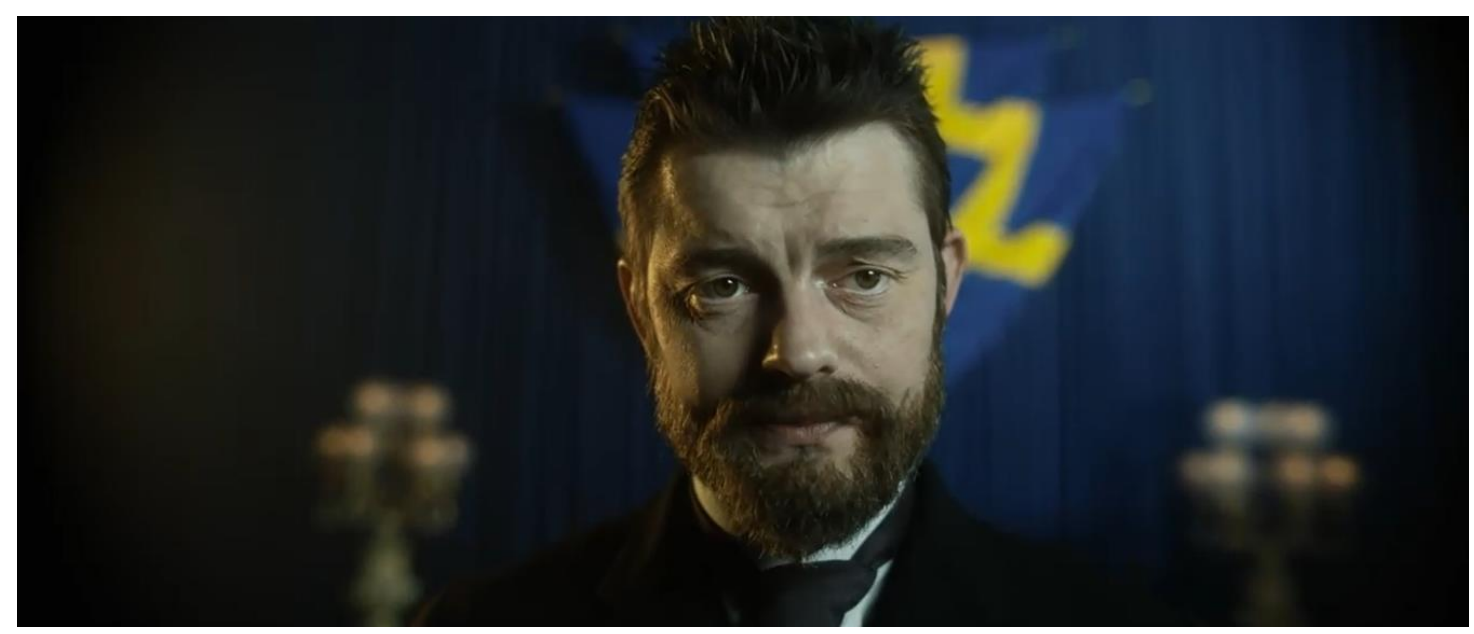

Fonte: Netflix (2021).

Pierre: É de se pensar que o rádio possa se tornar muito perigoso nas mãos erradas... Aqui, podemos questionar se a humanidade se beneficia de conhecer os segredos da natureza. Se está pronta para lucrar com ela, ou se esse conhecimento não será prejudicial... O exemplo das descobertas do Nobel é característico, pois explosivos de alta potência permitiam realizar um trabalho incrível. Eles são um terrível meio de destruição nas mãos de grandes criminosos que levariam o povo à guerra.

Na Figura 10, é relevante observar que Pierre discursa sozinho, sem a companheira ao seu lado. O discurso de Pierre evidencia seu receio de que o rádio possa ser utilizado de uma forma que gerasse conflitos à sociedade e seu desejo que a humanidade obtivesse mais bem do que mal com as novas descobertas. Dessa forma, como apontado por Silva \& Calafete (2021), a ciência possui mais de uma face e a cena supracitada ao trazer exemplos de eventos reais, contribui com a contextualização da ciência e revela outro potencial, o de gerar argumentações e compreensões de que a ciência serve aos interesses da sociedade, sendo influenciada por aspectos políticos, ambientais, econômicos e sociais.

\section{Considerações Finais}

Além da trajetória científica de Marie, o filme apresenta aspectos do romance vivido entre a cientista e seu marido Pierre; a inserção de aspectos da vida pessoal da cientista na história se dá como uma forma de envolver o público no enredo do filme, prendendo sua atenção e de certa forma desenvolvendo uma familiarização dos espectadores com a personagem. Esta familiarização com os espectadores faz com que os temas trabalhados sejam imaginados em seu próprio contexto, uma vez que as dificuldades enfrentadas, o casamento, a perda do ente querido fazem parte da realidade de muitas pessoas.

Os conceitos científicos abordados pelo filme, embora em alguns momentos sejam um tanto superficiais, se dão como introdutórios aos conteúdos e o modo como são apresentados proporciona o entendimento do tema para públicos de diversas idades e níveis de escolaridade, contribuindo assim, para a democratização do conhecimento científico. Também contribui para a desmistificação da ciência e dos próprios cientistas; da ciência por evidenciar seus processos e abordá-la como uma atividade humana e do cientista por colocar uma mulher como protagonista e principal responsável pelos feitos, evidenciando suas lutas, dificuldades, e injusta falta de reconhecimento.

Além dos pontos supracitados, o filme representa a ciência de uma forma diferente da geralmente vista pela comunidade. Traz a representação de uma comunidade científica que gera o entendimento de que a ciência é uma ação colaborativa; mostra que os âmbitos políticos, sociais e econômicos influenciam diretamente no modo como a ciência é feita e 
divulgada; e ainda compreende uma importante parte da história do desenvolvimento da química como a conhecemos na atualidade.

Sendo assim, pode-se compreender que a obra tem potencial para ser utilizada como um material de DC em atividades didáticas, desde que o professor, faça as articulações necessárias para atingir seus objetivos de ensino, considerando uma crítica reflexão de que a história pode promover debates e trazer temas que vão além do conteúdo especificado no currículo. Deste modo, além de um recurso de diversão, o filme Radioactive pode contribuir com a construção do processo de ensino e aprendizagem, sobretudo no que diz respeito a conceitos sobre química e física, podendo também ser um meio para aproximar tais conhecimentos do público que não está inserido diretamente no meio acadêmico.

No entanto, vale ressaltar que muitos aspectos do filme são fictícios e não condizem com a história da cientista, uma vez que é um filme comercial que prioriza o entretenimento do que representar com precisão os aspectos científicos (Santos \& Silva, 2021). Nesse sentido, a obra não se caracteriza como um filme didático e sim como uma narrativa romanceada, na qual na medida que apresenta fatos históricos, também apresentam cenas fictícias e fantasiadas.

Como sugestão para trabalhos futuros, considera-se que diversos filmes além do tratado neste trabalho, retratam demais ciências que estavam sendo desenvolvidas na mesma época. Assim, podem ser utilizados como recurso de DC e merecem uma análise crítica acerca de seus potenciais e suas formas de contribuição para a democratização do conhecimento. Outra possibilidade para trabalhos futuros é a construção de uma sequência didática envolvendo o filme, buscando discutir aspectos da ciência representado na obra com estudantes de nível médio ou superior, uma vez que "em tempos atuais, o professor necessita buscar metodologias alternativas de ensino, capazes de instigar o processo norteador do ensino e da aprendizagem dos discente" (Gonçalves, 2021, p.2).

\section{Referências}

Abud, K. M. (2003). A construção de uma Didática da História: algumas idéias sobre a utilização de filmes no ensino. História (São Paulo), 22, 183-193. https://www.scielo.br/j/his/a/jMrYY4HDZR8RwmNsqrWx7hK/?format=pdf\&lang=pt

Albuquerque, A. G., \& Silva, A. M. T. B. da. (2019). A mulher nas Ciências Naturais: uma história de enfrentamentos e conquistas. Research, Society and Development, 8(9), e37891311. https://doi.org/10.33448/rsd-v8i9.1311

Castelfranchi, Y. (2010) Por que comunicar temas de ciência e tecnologia ao público? (Muitas respostas óbvias... mais uma necessária). In: Massarani, L. (coord.). Jornalismo e ciência: uma perspectiva ibero-americana. Rio de Janeiro: Fiocruz /COC /Museu da Vida, 1, 13-21.

Costa, G. C. (2009). Discurso de divulgação científica cinematográfica: apontamentos sobre uma ciência encenada. In: Scherer (ORG.), A. E. et al. Tecnologias de linguagem e produção do conhecimento, 2, 78-90.

Cunha, M. B., \& Giordan, M. (2009b). A imagem da ciência no cinema. Química nova na escola, 31(1), 9-17. http://qnesc.sbq.org.br/online/qnesc31_1/03QS-1508.pdf

Cunha, M., \& Giordan, M. (2009a). A divulgação científica como um gênero de discurso: implicações em uma sala de aula. Anais In: Encontro Nacional de Pesquisa em Educação em Ciência, 7, 1-12.

Estrela, C. (2018). Metodologia Científica: Ciência, Ensino, Pesquisa. Editora Artes Médicas.

Ferreira, L. N. A., \& Queiroz, S. L. (2012). Textos de Divulgação Científica no Ensino de Ciências: uma revisão. ALEXANDRIA Revista de Educação em Ciência e Tecnologia, 5(1), 3-31. https://dialnet.unirioja.es/servlet/articulo?codigo=6170783

Fontanella, D., \& Meglhioratti. F. A. (2013). A divulgação científica e o ensino de ciências: análise das pesquisas. Maringá-PR. Anais VIII Encontro Internacional de Produção Científica.

Gonçalves, T. M. (2021). Cinema, câmera e ação: Utilizando um filme para o ensino de tópicos de Biologia no ensino médio. Research, Society and Development, 10(4), e58710414438. https://doi.org/10.33448/rsd-v10i4.14438

Kosminsky, L., \& Giordan, M. (2002). Visões de ciências e sobre cientista entre estudantes do ensino médio. Química nova na escola, 15(15), 11-18. http://qnesc.sbq.org.br/online/qnesc15/v15a03.pdf

Lima, G. S., \& Giordan, M. (2017). Propósitos da Divulgação Científica no Planejamento de Ensino. Revista Ensaio, 19, 1-23. https://doi.org/10.1590/198321172017190122

Lisboa, J. C., Almeida, R., Gonçalves, E. N. C., \& Campos, C. R. P. A. (2015). A contribuição dos desenhos animados para a divulgação e construção da cultura científica. In.: Campos, C. R. P. (Organizador). Divulgação Científica e Ensino de Ciências: Debates Preliminares. Editora Ifes. 
Research, Society and Development, v. 11, n. 2, e0311224995, 2022

(CC BY 4.0) | ISSN 2525-3409 | DOI: http://dx.doi.org/10.33448/rsd-v11i2.24995

Mesquista, N. A. S., \& Soares, M. H, F. B. (2008). Visões de ciência em desenhos animados: uma alternativa para o debate sobre a construção do conhecimento científico em sala de aula. Ciência \& Educação (Bauru), 14, 417-429. https://doi.org/10.1590/S1516-73132008000300004

Mól, G, S. (2017). Pesquisa qualitativa em ensino de química. Revista Pesquisa Qualitativa, 5(9), 495-513. https://editora.sepq.org.br/rpq/article/view/140.

Moraes, R. (2003). Uma tempestade de luz: A Compreensão possibilitada pela análise textual discursiva. Ciência \& Educação, 9(2), 191-211. https://www.scielo.br/j/ciedu/a/SJKF5m97DHykhL5pM5tXzdj/?format=pdf\&lang=pt

Moran, J. M. (1995). O vídeo na sala de aula. Comunicação \& Educação, 1(2), 27-35. https://doi.org/10.11606/issn.2316-9125.v0i2p27-35

Nascimento, T. G., \& Rezende, J. M. F. (2010). A produção sobre divulgação científica na área de educação em ciências: referenciais teóricos e principais temáticas. Investigações em Ensino de Ciências, 15(1), 97-120. https://www.if.ufrgs.br/cref/ojs/index.php/ienci/article/view/317

Pereira A. S., \& Shitsuka, D. M., \& Parreira, F. J., \& Shitsuka R. (2018). Metodologia da pesquisa científica. Santa Maria/RS.

Pin, J. R. O., Faria, R. S. F., \& Gimenes, S. S. (2015). Divulgação Científica no contexto da Educação Básica. In.: Campos, C. R. P. (Organizador). Divulgação Científica e Ensino de Ciências: Debates Preliminares. Editora Ifes, 24.

Pinheiro, R. M., \& Londero, L. (2021). "Marie Curie - A coragem do conhecimento": uma possibilidade na discussão de aspectos da natureza da ciência. Revista Valore, 6, 1558-1569. https://doi.org/10.22408/reva6020218961558-1569

Reznik, G., Massarani, L., \& Moreira, I. C. (2019). Como a imagem de cientista aparece em curtas de animação? História, Ciências, Saúde-Manguinhos. 26, 753-777. https://doi.org/10.1590/S0104-59702019000300003.

Rocha, M. B. (2010). Textos de divulgação científica na sala de aula: a visão do professor de ciências. Revista Augustus, 14(29), 24-34.

Santos, C. A., \& Silva, L. L. (2021). A história que o filme Radioactive não conta e a percepção de alunos de licenciatura em física. Revista Brasileira de Ensino de Física, 43. https://doi.org/10.1590/1806-9126-RBEF-2021-0037

Silva, H. C. O. (2006). O que é divulgação científica? Ciência \& Ensino, 1(1).

Silva, J. A., \& Kawamura, M. R. D. (2001). A natureza da luz: Uma atividade com textos de divulgação científica em sala de aula. Caderno Catarinense de Ensino de Física, 18(3), 317-339. https://doi.org/10.5007/\%25x

Silva, J., \& Calafate, L. (2021). Cinema e divulgação científica. Revista de Ciência Elementar, 9(2). 1-7. doi.org/10.24927/rce2021.033

Sousa, M. C. F. de, Cicuto, C. A. T., \& Lucchese, M. M. (2020). O cinema no Ensino de Ciências da Natureza: análise do filme "As aventuras de Sammy". Research, Society and Development, 9(9), e232997026. https://doi.org/10.33448/rsd-v9i9.7026

Silva, S. C. H. (2009). A divulgação científica no contexto social e escolar. Olhares \& Trilhas, 5(1). https://seer.ufu.br/index.php/olharesetrilhas/article/view/3579/2622

Suppia, A. L. P. O. (2006). A divulgação científica contida nos filmes de ficção. Ciência e Cultura, 58(1), 56-58. http://cienciaecultura.bvs.br/pdf/cic/v58n1/a24v58n1.pdf

Vicentino, S. L., \& Sant'ana, D. M. G. (2010), A Divulgação Científica por meio de filmes: a experiência da parceria entre o Museu Dinâmico Interdisciplinar e o Programa de Pós-graduação em Biociências aplicadas à Farmácia. Arquivos do MUDI, 14(1), 27-32. https://periodicos.uem.br/ojs/index.php/ArqMudi/article/view/20415 